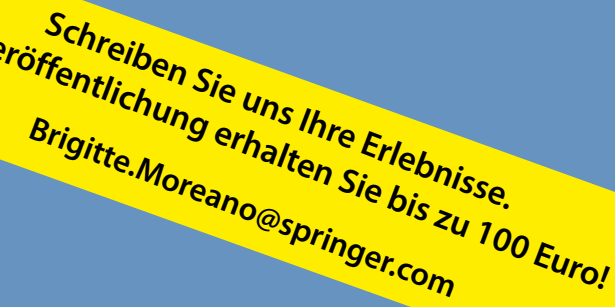

Ärztliche Erfahrung beschränkt sich nicht auf medizinisches Fachwissen. Sie entsteht auch aus den mehr oder minder alltäglichen, heiter, ärgerlich oder nachdenklich stimmenden Erlebnissen mit Patienten, Kollegen und Mitarbeitern. Senden Sie uns Ihre Geschichte an: Brigitte.Moreano@springer.com. Für jeden veröffentlichten Text erhalten Sie bis zu 100 Euro.

\title{
Ungewöhnliche Differenzialdiagnose
}

— Dienstagabend. Bereitschaftsdienst in einer unterfränkischen Kleinstadt. Gegen 20 Uhr werde ich angerufen. Die Disponentin der Bereitschaftsdienstzentrale bittet mich um einen Hausbesuch in einem der beiden örtlichen Pflegeheime. Einem der dortigen Bewohner sei tagsüber die Trachealkanüle gewechselt worden. Seitdem leide er unter Luftnot und Erbrechen.

Das Pflegepersonal der Spätschicht berichtet mir vor Ort, der Bewohner, Herr R., solle in wenigen Tagen in ein heimatnäheres Pflegeheim umziehen. Da der HNO-Arzt vor diesem Termin wegen der Ferien nicht mehr kommen könne um die Trachealkanüle wie üblich zu wechseln, hätte der Pflegedienstleiter - der dazu auch ausgebildet ist - die Trachealkanüle gewechselt. Im Lauf des Tages sei Herr R. immer unruhiger geworden, er hätte offensichtlich Atemprobleme. In der letzten Stunde habe er erbrochen und aus dem Tracheostoma sei Flüssigkeit gekommen, die der Sondenkost ähnelte.

Die gerade eintreffende Nachtschwester bittet mich, den Bewohner - übrigens in Isolation wegen eines multiresistenten Erregers - ins Krankenhaus einzuweisen, da sie sich um 60 Bewohner kümmern müsse. Als erste Maßnahme bei PEG-Patienten mit Erbrechen empfehle ich den Stopp der Sondenkost und das Offenlassen der Sonde, um den Mageninhalt zu entleeren und so den Druck aus dem Magen zu nehmen. Offenbar ist der intragastrale Druck nicht erhöht, jedenfalls entleert sich kein Mageninhalt aus der diskonnektierten Sonde.

Bei der Auskultation findet sich eine seitengleich regelrecht belüftete Lunge. Aus

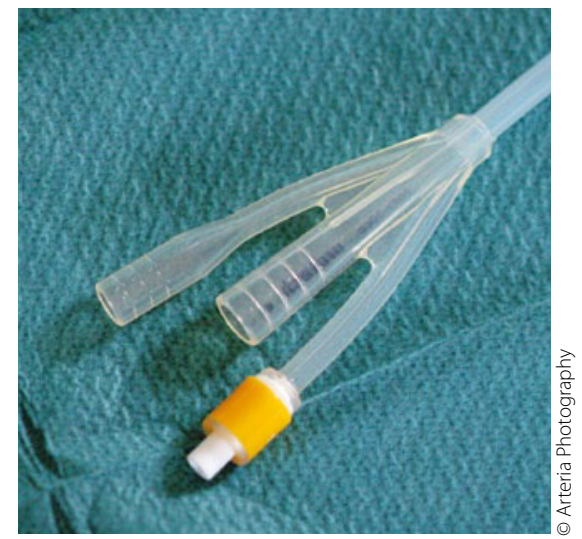

Auch ein verstopfter Blasenkatheter kann Atemnot verursachen.

der Trachealkanüle kann kein vermehrtes Sekret und auch keine Sondenkost abgesaugt werden. Den Mundbereich hatte die Pflegerin nach dem Erbrechen schon abgesaugt.

Bei der Untersuchung des Abdomen erzählt mir die anwesende Pflegerin, sie habe im Verlauf der Schicht bemerkt, dass die Kompresse des suprapubischen Dauerkatheters nass sei und sie schon mehrfach (!) gewechselt. Ein Test mit der Blasenspritze bestätigt meinen Verdacht auf einen verstopften Katheter. In Ermangelung eines Wechselsets lege ich einen transurethralen Katheter. Bis ich den Papierkram erledigt habe entleeren sich $800 \mathrm{ml}$ trüber Urin in den Beutel. Der Patient liegt entspannt im Bett. Die anfangs skeptische Pflegerin bestätigt: „Jetzt ist er wie immer“.

Aus der ersten Verdachtsdiagnose Dyspnoe nach möglicherweise nicht sachgerechtem TK-Wechsel, wird über den Umweg Gastroenteritis (da gerade in der Umgebung grassierend) die Diagnose Harnverhalt bei verlegtem suprapubischem Katheter. Ob man im Krankenhaus wohl auch innerhalb einer halben Stunde darauf gekommen wäre?

Michael STEINHAUER, INTERNIST, GEMÜNDEN -

\section{Darmschlingen im Rucksack}

_ Es war im Institut für Pathologie der Medizinischen Hochschule üblich, dass der Obduzent den Sektionsbefund auf ein Tonband sprach und es anschließend von einer Sekretärin abschreiben ließ. Zu DDR-Zeiten waren die Sekretärinnen aber unterbezahlt, nicht ausgebildet und meist von jeder Sachkenntnis ungetrübt. So war in einem Sektionsbericht zu lesen: „Die Leiche trug die Darmschlingen im Rucksack!"
Bei der darauf folgenden Aussprache konnte die Kollegin nichts fehlerhaftes an ihrer Aussage erkennen, so dass sich die Institutsleitung entschloss, trotz Arbeitskräftemangel das Anstellungsverhältnis aufzuheben.

MR Dr. MED. hABIL. BERND SCHULZE, ERFURT . 